\title{
The Use of a Mixture of Hypericum Perforatum and Azadirachta indica for the Management of Diabetic Foot Ulcers: A Case Series
} Maria Letizia labichella*

Helios Med Onlus, International Health Cooperation, Pozzallo (RG), Italy

\begin{abstract}
Introduction: Diabetic foot ulcers (DFU) represent a growing health care issue worldwide, representing one of the most dramatic consequences of poorly controlled diabetes. A first successful experience on a patient with extremely advanced feet ulcers treated with a mixture of Hypericum perforatum and Azadirachta indica (Hyperoil ${ }^{\mathrm{TM}}$ ) has induced us to use the same treatment on a series of patients with less severe ulcers. Aim of this report is to summarize the results observed in this case series.

Methods: All patients afferent to the Wound Care Units of Pisa, Ragusa and Modena - Italy (WCU) from June 2012 to June 2013 followed a standardized diagnostic/therapeutic scheme to manage diabetes and coexisting conditions. All DFUs were treated with Hyperoil ${ }^{\mathrm{TM}}$ at home, when diabetes was well compensated at WCU. Changes in $\mathrm{HbA} 1 \mathrm{c}$, pressure and pain have been evaluated using paired t-test.

Results: All the 16 patients recovered their DFUs 2 to 10 months after starting Hyperoil ${ }^{\mathrm{TM}}$ treatment. During this period $\mathrm{HbA} 1 \mathrm{c}$ improved and pain due to DFUs disappeared in all patients; furthermore, hypertension was better compensated.

Conclusion: These preliminary results, belonging to a case series, suggest that using Hyperoil ${ }^{\mathrm{TM}}$ for advanced diabetic foot ulcers, together with tight diabetes control, might be a cheap and effective new option for the home management of advanced diabetic foot ulcers.
\end{abstract}

Keywords: Diabetic foot ulcer; Hypericum perforatum; Azadirachta indica; Wound care unit; Home wound care; Management of advanced diabetic foot ulcers; Diabetes

\section{Introduction}

Diabetes affected 171 million people worldwide in 2000; this number is expected to duplicate in 2030, when WHO estimate 366 million cases [1]. These numbers are even more dramatic in developing countries as Africa, Eastern Mediterranean and South-East Asian Regions, where the prevalence is expected to be close to triple in the same timeframe [1], thus becoming a pandemic issue moving from richest countries to worldwide population. A systematic review on the prevalence of diabetes and its complications in Northern Africa found that diabetes prevalence ranged from $2.6 \%$ in rural Sudan to $20.0 \%$ in urban Egypt and, in general, was significantly higher in urban areas than in rural areas. The same study showed that undiagnosed diabetes ranges from $18 \%$ to $75 \%$ [2].

The potential risks linked with advanced diabetes, especially when uncontrolled or poorly controlled, are well recognized: only $3.6 \%$ of patients achieve the three American Diabetes Association (ADA) recommended targets for blood pressure, LDL cholesterol, and HbAlc in poor countries like Latin America [3]. The prevalence of chronic diabetes complications in North Africa ranged from $8.1 \%$ to $41.5 \%$ for retinopathy, $21 \%$ to $22 \%$ for albuminuria, $6.7 \%$ to $46.3 \%$ for nephropathy and $21.9 \%$ to $60 \%$ for neuropathy [2].

Advanced complications of diabetes, including diabetic foot ulcer, constitutes a major challenge, especially in low-income countries, and can have a huge impact on patients, families, and society [2].

Improvements in foot ulceration diagnosis and prevention can reduce amputation risk and reduce health care costs [3] but, for example, $6.7 \%$ of subjects with diabetes consulted a health care professional for diabetic foot in 2009 in Chile [4].
World Health Organization, WHO, has developed some recommendations, including regular foot inspection and care, to reduce the incidence of diabetic foot ulcers [5], responsible for up to $70 \%$ of amputations in adults [4]. Basic diabetes management and care are estimated reducing up to $80 \%$ of all diabetic foot amputations [5]. The yearly direct costs of diabetes in the USA were \$164 billion in 2007 [6], at least one-third linked with the treatment of diabetic foot ulcers [7].

The appearance of foot ulcers almost always worsens glycaemia because of the infections that are difficult to be controlled [8]. As diabetic wounds are burdened by severe impairment of local microcirculation, they're linked with an increased risk of infections. Infections let glycaemic control even more difficult than before, in a patient that is, almost always, poorly controlled. A negative loop between ulcer worsening, metabolic worsening, and difficulty of patient's treatment starts, and can take the patient to foot amputation [9].

If possible, open or endovascular revascularization is attempted. Ulcer debridement defined as the removal of foreign debris and devitalized or contaminated tissues from a wound bed so that the surrounding healthy tissues are exposed [10], is frequently needed; as

*Corresponding author: Maria Letizia labichella, Helios Med Onlus, Pozzallo (RG) Italy, Tel: +39 3663234494; Fax: +39 50 5555534; E-mail: ml.iabichella@gmail.com

Received December 09, 2014; Accepted January 12, 2015; Published January 31, 2015

Citation: labichella ML (2015) The Use of a Mixture of Hypericum Perforatum and Azadirachta indica for the Management of Diabetic Foot Ulcers: A Case Series. J Diabetes Metab 6: 499. doi:10.4172/2155-6156.1000499

Copyright: (c) 2015 labichella ML. This is an open-access article distributed under the terms of the Creative Commons Attribution License, which permits unrestricted use, distribution, and reproduction in any medium, provided the original author and source are credited. 
ulcers often degenerate, periodical debridement have to be performed [9].

Thus, diabetic foot lesions should need a treatment that prevents and, possibly, treat infections while stimulating tissue repair [9].

Hyperoil" is a mixture of hypericum flowers extract (Hypericum perforatum) and nimh oil (Azadirachta indica) produced by RIMOS S.r.L. Mirandola (MO) - Italy (Medical Device Class IIB CE0476). A case report on the successful use of Hyperoil ${ }^{\mathrm{w}}$ in an elderly patient with advanced bilateral diabetic foot has been recently published [11]. The use of Hyperoil" in this patient allowed wound home care, when the patient received only a 2 times a week cleaning of the lesions, performed by relatives, without any other surgical or clinical intervention [11]. There were no changes in any other treatment of the patient, while ulcer management paralleled with significant improvements in glycaemic control (HbAlc between seven point six percent and seven point seven percent) [11].

Learning from this experience, where Hyperoil" seem to be an effective and cheap therapy for advanced diabetic foot ulcers that, for the first time, allow home caring without the intervention of highly specialized personnel and with a significant reduction of surgeries, the use of Hyperoil" was started on all patients afferent to the Wound Care Units of Pisa, Ragusa and Modena - Italy (WCU) with diabetic ulcers. Results obtained after up to 1 year follow up will be described in this article.

\section{Methods}

All patients with advanced diabetic foot ulcer [12] afferent to WCU from June 2012 to June 2013 followed the diagnostic/therapeutic scheme described in Figure 1, being the standard management on all patients with diabetic foot lesions followed at WCU from 1993 [13].

Patients with critical chronic ischemia, having supine big toe pressure (Laser Doppler evaluation) $<30 \mathrm{mmHg}$ associated to dorsum foot values $\mathrm{O}_{2}<20 \mathrm{mmHg}$ and $\mathrm{CO}_{2}>50 \mathrm{mmHg}$ (Transcutaneous Partial Pressure) measured with the lower limb depending [14,15], were not included in this case series.

All patients, first of all, had the best medical treatment according with ADA guidelines for diabetes [16], stroke prevention [17,18], and for their disease or, more commonly, diseases. Then, they all performed echo-colour-Doppler. If the results did not highlight abnormalities, the patient had wound care. If not, transcutaneous oxygen and carbon dioxide partial pressure, laser-Doppler and bio-microscopic evaluations were performed. After these assessments, depending on their results, angiography and revascularization or Iloprost trometamol (Iloprost trometamol $0.067 \mathrm{mg}$ equivalent to iloprost $0.050 \mathrm{mg}$ diluted in 250 $\mathrm{ml}$ of normal ringer solution, infused using a pump-syringe for 12-24 hours) treatment were performed according with Leriche-Fointaine clinical classification $[19,20]$, on the same day of first visit. If patients didn't respond to Endoprost, angiography and revascularization were performed, too. In any case, all patients had wound care.

Hyperoil" was used on foot ulcers not yet needing surgical procedures. Patients started their treatment with Hyperoil" in the WCU. Each wound was accurately cleaned-up with physiologic solution before the application of Hyperoil". Then, the lesion was protected with non-adhesive gauze and accurately bandaged [21]. Dressing was changed every two days. These are very simple and simple to teach procedures, so dressing changes and sequent Hyperoil" applications were performed at home, usually by nurses or relatives. Patients were asked to attend periodical clinical medical checks (normally every month) in WCU, to assess metabolic status and ulcer's progression, and to update therapies accordingly.

Clinical and demographic data were collected, including full medical history, on-going treatments, comorbidities (diagnosed on anamnestic analysis), age, smoking habits. Previous treatments for foot ulcers were collected, if appropriate.

All patients were controlled for metabolic parameters with the goal of optimizing glycaemic control, having target $\mathrm{HbAlc}$ of $7 \%$ and fasting blood glucose between $80 \mathrm{mg} / \mathrm{dL}$ and $120 \mathrm{mg} / \mathrm{dL}$, according with ADA guidelines [16].

All patients were asked to evaluate their perceived pain administering Visual Analog Scale for pain (VAS) [22].

Patients continued to be treated with this approach at WCU, but the results obtained in all patients enrolled in the first year were decided to be disclosed because of the consistency of the outcomes. All patients were followed-up until June 2014.

All patients gave their signed informed consent to be included in this case series.

Because of the nature of observed patients and outcome, only descriptive statistic was used to evaluate outcomes. Statistical significance of variations between the beginning of the observation, the lesion recovery and the end of the observation, as the ones on variations between the lesion recovery and the end of the observation, have been evaluated with paired samples t-test performed with Microsoft Excel 2010 for Windows.

\section{Results}

A total of 16 (9 males, 7 females) diabetic patients with advanced foot ulcer were observed. Their age ranged between 46 and 78 years and 7 of them were actual smokers. All patients were under antihypertensive therapy (average Systolic Blood Pressure [SBP] 144.8 mmHg; SD 13.8 mmHg; min: 128; max: 170. Average Diastolic Blood Pressure [DBP] $91.1 \mathrm{mmHg}$; SD $6.6 \mathrm{mmHg}$; min 82; max: 102), 11 PAOD, 9 ischemic heart failure (IHF), 5 Chronic Kidney Failure (CKF), 3 Chronic Obstructive Pulmonary Disease (COPD) and 1 was HCV positive.

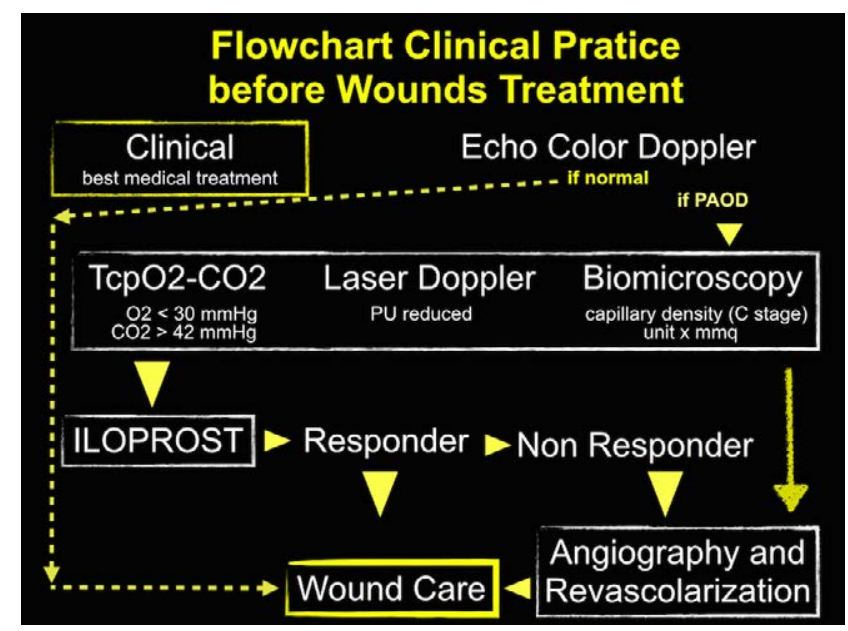

Figure 1: WCU diabetic foot ulcer management flowchart. TcpO2-CO2 Transcutaneous Partial Pressure Oxygen-Carbon Dioxide measured with supine dorsum foot; PU: Perfusion Unit; PAOD: Peripheral Arterial Occlusive Disease; $C$ stage: according to Fagrell and Lundberg stage classification for evaluating the nutritive skin capillaries. 
The foot ulceration area varied from 10 to $420 \mathrm{~cm}^{2}$. Most of the ulcers were really deep and advanced, having 14 of the 16 patients lesions with bone exposition. All patients received antibiotic therapy at WCU admission administering a rifamycin or specific antibiotics determined after the identification of the infective agent and antibiogram test.

All patients were shifted to intensive insulin therapy when admitted to WCU, using insulin glargine as basal insulin, administered at bedtime, and insulin as part or insulin lispro administered at breakfast, lunch and dinner after checking fasting glycaemic levels to determine the most appropriate dosage according with clinical experience. No changes in dietary habits were prescribed. HbAlc at baseline ranged between $8.8 \%$ and $14.0 \%$ (average $11.2 \%$; SD 1.7\%) (Table 1).

The average VAS value was 7.2 (SD 2.5) ranging between 2 and 10 (Table 1). All patients used painkillers as treatment.

All patients performed echo-colour-Doppler, bio-microscopy and transcutaneous oxygen and carbon dioxide partial pressure evaluation. Angiography was also performed on the eight patients not responding to Iloprost trometamol and laser-Doppler fluximetry on 6 nonamputated ones.

These exams permitted to understand foot lesions genesis. Five patients had a neuropathic injury without PAOD (Figure 2A), 4 had a neuropathic injury with PAOD (Figure $2 \mathrm{~B}$ ) while the remaining 7 patients had a distal ischemic injury with PAOD (Figure 2C), being the most difficult and advanced lesions to be approached.

Ten of the all the 16 patients have had a previous minor amputation; the distribution by foot ulcer genesis is described in Table 2 .

All patients had very advanced foot ulcers that, following the usual approach, would need intensive treatments including surgery (in most cases multiple), hospitalizations or, at least, home care performed by a specialist.

All patients were treated with Hyperoil" only. Eleven of these patients were also treated with Iloprost trometamol after angiography, 4 had a revascularization after angiography and 10 of the 11 patients treated with Iloprost trometamol had also surgical debridement in addition to Hyperoil" treatment. Two patients with both distal ischemic injury and PAOD had both angiography and the surgical debridement.

All the 16 patients recovered their foot ulcers 2 to 10 months after starting Hyperoil" treatment. None of the patients was lost to followup. Some examples of recovered lesions are shown in Figure 3.

None of the patients had gangrene progression or new wounds in the observed period, being at 3, 6 and 12 months after ulcer recovery. Only one patient had a local infection that was treated with an additional washing and a daily administration of Hyperoil" .

All patients reported a clinically relevant and statistically significant improvement in HbAlc (Figure 4) when ulcers recovered (Table 1) (average $7.8 \%$; SD $0.7 \%$; $<<0.01$ ) when compared to baseline.

Patients reported an average clinically relevant and statistically significant improvement in SBP (average $135.0 \mathrm{mmHg}$; SD $7.4 \mathrm{mmHg}$; $\mathrm{p}=0.02$ vs. baseline) (Figure 5) and DBP (average $84.0 \mathrm{mmHg}$; SD 6.4 $\mathrm{mmHg} ; \mathrm{p}=0.01$ vs. baseline) (Figure 6) when ulcers recovered (Table 1), without any change in antihypertensive therapy. Even under tight control, one patient worsened and three remained almost stable, but ulcer recovery was not influenced by pressure unsatisfactory compensation.

All patients reported no pain on VAS both at ulcer recovery and

\begin{tabular}{|c|c|c|c|c|c|c|c|c|c|c|c|}
\hline $\begin{array}{l}\text { Patient } \\
\text { Number }\end{array}$ & $\begin{array}{l}\text { HbA1c basal } \\
(\%)\end{array}$ & $\begin{array}{c}\text { HbA1c } \\
\text { at lesion } \\
\text { recovery } \\
(\%)\end{array}$ & $\begin{array}{l}\text { HbA1c at the } \\
\text { end of the } \\
\text { obesrvation } \\
(\%)\end{array}$ & $\begin{array}{l}\text { SBP basal } \\
(\mathrm{mm} \mathrm{Hg})\end{array}$ & $\begin{array}{c}\text { SBP at the } \\
\text { end of the } \\
\text { observation } \\
(\mathrm{mmHg})\end{array}$ & $\begin{array}{c}\text { DBP basal } \\
(\mathrm{mmHg})\end{array}$ & $\begin{array}{l}\text { DBP at } \\
\text { lesion } \\
\text { recovery } \\
(\mathrm{mmHg})\end{array}$ & $\begin{array}{l}\text { DBP at the } \\
\text { end of the } \\
\text { observation } \\
(\mathrm{mmHg})\end{array}$ & VAS basal & $\begin{array}{l}\text { VASat the } \\
\text { end of the } \\
\text { observation }\end{array}$ & $\begin{array}{l}\text { VASat the } \\
\text { end of the } \\
\text { observation }\end{array}$ \\
\hline 1 & 11.5 & 7.1 & 7.6 & 134.0 & 132.0 & 86.0 & 78.0 & 82.0 & 5.0 & 0.0 & 0.0 \\
\hline 2 & 13.7 & 7.7 & 7.4 & 160.0 & 140.0 & 84.0 & 80.0 & 88.0 & 4.0 & 0.0 & 0.0 \\
\hline 3 & 9.6 & 7.4 & 7.6 & 154.0 & 136.0 & 94.0 & 84.0 & 84.0 & 10.0 & 0.0 & 0.0 \\
\hline 4 & 10.8 & 7.8 & 7.1 & 132.0 & 134.0 & 90.0 & 76.0 & 86.0 & 5.0 & 0.0 & 0.0 \\
\hline 5 & 11.0 & 8.0 & 7.6 & 142.0 & 138.0 & 96.0 & 82.0 & 86.0 & 6.0 & 0.0 & 0.0 \\
\hline 6 & 11.2 & 7.3 & 7.3 & 128.0 & 126.0 & 90.0 & 78.0 & 86.0 & 10.0 & 0.0 & 0.0 \\
\hline 7 & 14.0 & 9.4 & 9.4 & 170.0 & 146.0 & 102.0 & 78.0 & 96.0 & 7.0 & 0.0 & 0.0 \\
\hline 8 & 9.0 & 7.7 & 7.7 & 132.0 & 128.0 & 84.0 & 92.0 & 92.0 & 10.0 & 0.0 & 0.0 \\
\hline 9 & 8.8 & 7.6 & 7.6 & 148.0 & 126.0 & 88.0 & 102.0 & 80.0 & 6.0 & 0.0 & 0.0 \\
\hline 10 & 9.6 & 7.7 & 7.7 & 150.0 & 138.0 & 86.0 & 84.0 & 90.0 & 8.0 & 0.0 & 0.0 \\
\hline 11 & 11.6 & 7.1 & 7.1 & 144.0 & 130.0 & 84.0 & 88.0 & 76.0 & 9.0 & 0.0 & 0.0 \\
\hline 12 & 112.0 & 8.6 & 8.6 & 130.0 & 148.0 & 86.0 & 86.0 & 90.0 & 6.0 & 0.0 & 0.0 \\
\hline 13 & 11.6 & 7.4 & 7.4 & 128.0 & 136.0 & 84.0 & 84.0 & 84.0 & 2.0 & 0.0 & 0.0 \\
\hline 14 & 14.0 & 7.4 & 7.4 & 168.0 & 142.0 & 102.0 & 86.0 & 90.0 & 10.0 & 0.0 & 0.0 \\
\hline 15 & 11.0 & 6.8 & 6.8 & 154.0 & 130.0 & 90.0 & 84.0 & 84.0 & 10.0 & 0.0 & 0.0 \\
\hline 16 & 9.2 & 7.1 & 7.1 & 142.0 & 136.0 & 98.0 & 82.0 & 82.0 & 7.0 & 0.0 & 0.0 \\
\hline Mean & 11.2 & 7.8 & 7.6 & 144.8 & 135.0 & 91.1 & 84.0 & 86.0 & 7.2 & 0.0 & 0.0 \\
\hline Sd & 1.7 & 0.7 & 0.6 & 13.8 & 6.6 & 6.4 & 6.4 & 5.0 & 2.5 & 0.0 & 0.0 \\
\hline $\min$ & 8.8 & 7.0 & 6.8 & 128.0 & 126.0 & 82.0 & 76.0 & 76.0 & 2.0 & 0.0 & 0.0 \\
\hline $\max$ & 14.0 & 9.6 & 9.4 & 158.0 & 148.0 & 102.0 & 102.0 & 96.0 & 10.0 & 0.0 & 0.0 \\
\hline$p$ vs basal & & 0.0 & 0.0 & 0.0 & 0.0 & & 0.0 & 0.0 & & 0.0 & 0.0 \\
\hline $\begin{array}{c}p \text { vs } \\
\text { recovery }\end{array}$ & & & 0.1 & & 0.8 & & & 0.4 & & 0.0 & 0.0 \\
\hline
\end{tabular}

Table 1: HbA1c (\%), SBP $(\mathrm{mmHg})$, DBP $(\mathrm{mmHg})$, VAS at baseline, at lesion recovery and at the end of the observation period. SBP: Systolic Blood Pressure; DBP Diastolic Blood Pressure; SD: Standard Deviation; Min: Minimum; Max: Maximum. 


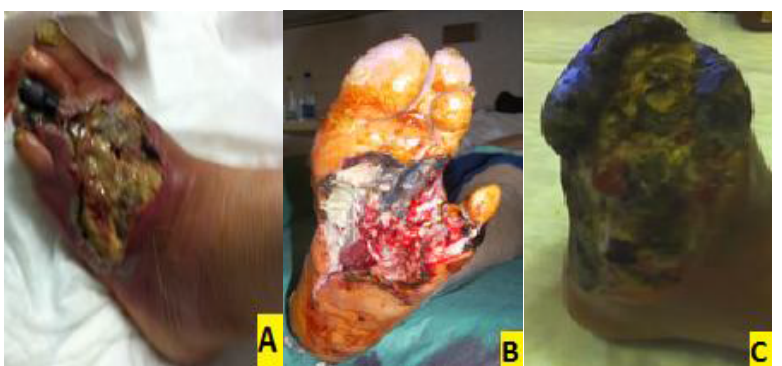

Figure 2: Examples of neuropathic diabetic foot ulcer without PAOD (A): neuropathic diabetic foot ulcer with PAOD $(B)$ : and distal ischemic diabetic foot ulcer with PAOD (C): PAOD: Peripheral Arterial Occlusive Disease.

\begin{tabular}{|c|c|c|c|}
\hline & $\begin{array}{c}\text { Neuropatic } \\
\text { diabetic foot } \\
\text { ulcer without } \\
\text { PAOD }\end{array}$ & $\begin{array}{c}\text { Neuropatic } \\
\text { diabetic foot } \\
\text { ulcer with } \\
\text { PAOD }\end{array}$ & $\begin{array}{c}\text { Distal ischemic diabetic foot } \\
\text { ulcer with PAOD }\end{array}$ \\
\hline N & 5 & 4 & 7 \\
\hline $\begin{array}{c}\text { Previous minor } \\
\text { amputations (N) }\end{array}$ & 2 & 3 & 5 \\
\hline
\end{tabular}

Table 2: Patient's distribution by neuropathic foot ulcer genesis and previous minor amputations. PAOD: Peripheral Arterial Occlusive Disease.
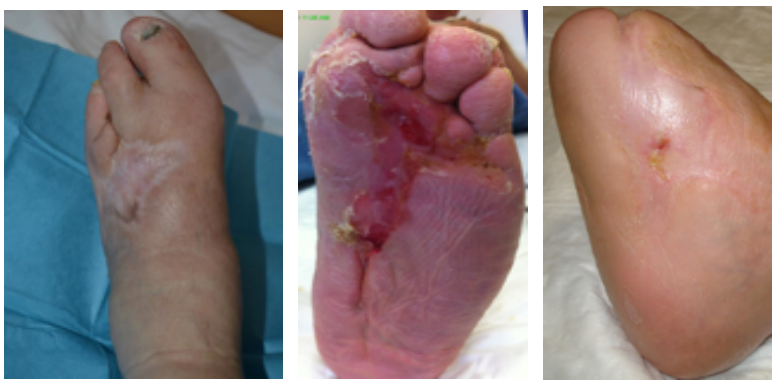

Figure 3: Examples of foot ulcer recovery.

at the end of the observation period (Figure 7) and none of them used painkillers in this period.

$\mathrm{HbA1c}$ remained stable between ulcers recovery and the end of the observation for each patient as blood pressure, and all patients remained pain free (Table 1). In this period insulin dosage was revised at all control visits; two patients with neuropathic diabetic foot ulcer without PAOD and one of the non-neuropathic patients with PAOD were shifted from insulin therapy to oral antidiabetic therapy with metformin, because of the improved diabetes control. None of the patients had any new ulcer or recurrence in the follow-up period.

\section{Discussion}

The observed case series support the hypothesis that Hyperoil might be used at home without the continuous assistance of specialized personnel for the satisfactory management of diabetic foot ulcers.

This was clearly not due to the direct effect of Hyperoil" but might be linked with the reduction of infections, the improved patient's surveillance and the increased motivation of these very difficult patients that, after a long period of continuous worsening of their health, experienced some sort of recovery in one of the most impacting of their multiple diseases. Furthermore, as patients were at home, caregivers (mainly relatives) felt more responsible about their role in supporting patients. This could have interrupted the negative feedback cycle linked with the appearance of diabetic foot ulcers, linking diabetes control with ulcers progression and infection. Furthermore, the possibility of managing diabetes wounds at home, instead than hospitalizations needed for surgical treatments of diabetic foot ulcers, should have contributed to treatments compliance and, thus, to general diabetes management.

According with ADA guidelines, the main strategy for the prevention and treatment of diabetic foot ulcers remains an adequate glycaemic control [16]. Several other options have been tested for the treatment of this invalidating complication of diabetes. Nutrition supplementation, including curcumin, L-Arginine, or vitamin E, have not proven a substantial efficacy [23]. The intra-lesional administration of human recombinant epidermal growth factor has shown the presence of complete granulation in $75 \%$ of patients after 5 months of treatment and re-epithelisation in $61 \%$ of cases after 1.2 years; amputations were needed in $12 \%$ of cases [24]. A large cohort study has shown that the use of lipid lowering medications reduces the risk of lower extremity amputations by $35-43 \%$ [25]. The use of Hydrogel dressings has been found having significantly greater effect on ulcer healing than larval therapy or platelet-derived growth factors [26] as some other treatments are under evaluation [27-34].

\section{HbA1c variations for each patient - baseline vs lesion recovery time}

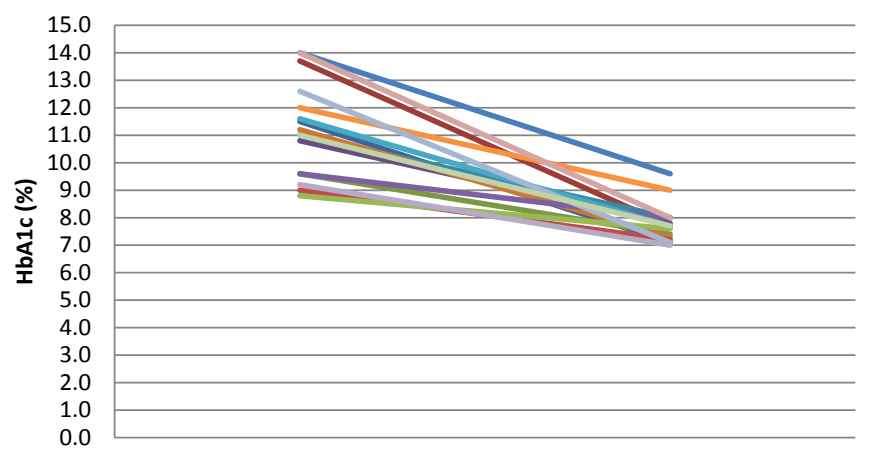

Figure 4: $\mathrm{HbA} 1 \mathrm{c}$ values for each patient at baseline and at foot ulcer recovery.

\section{SBP variations between baseline and ulcers recovery}

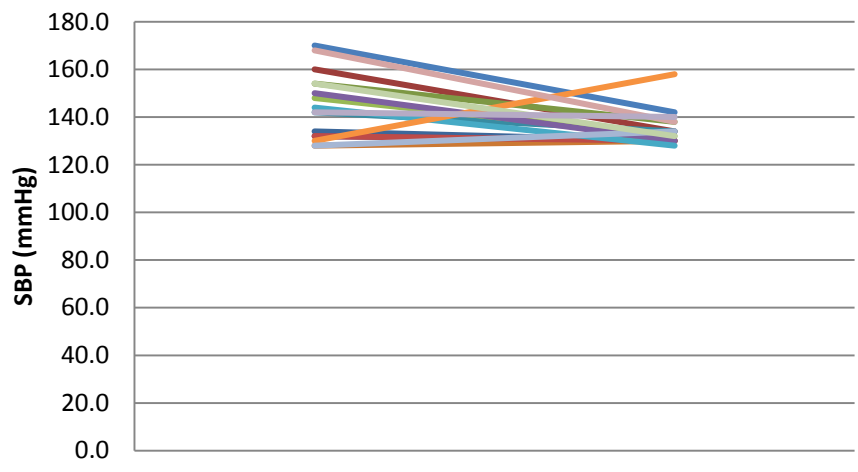

Figure 5: SBP values for each patient at baseline and at foot ulcer recovery. SBP: Systolic Blood Pressure. 
Citation: labichella ML (2015) The Use of a Mixture of Hypericum Perforatum and Azadirachta indica for the Management of Diabetic Foot Ulcers: A Case Series. J Diabetes Metab 6: 499. doi:10.4172/2155-6156.1000499

Page 5 of 6

\section{DBP variations between baseline and ulcers recovery}

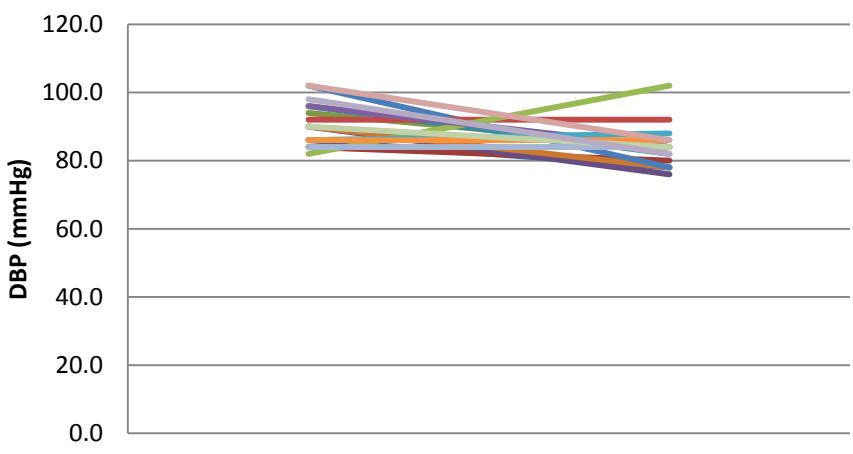

Figure 6: DBP values for each patient at baseline and at foot ulcer recovery DBP: Diastolic Blood Pressure.

\section{Pain perceived at baseline and at ulcer recovery measured through VAS score}

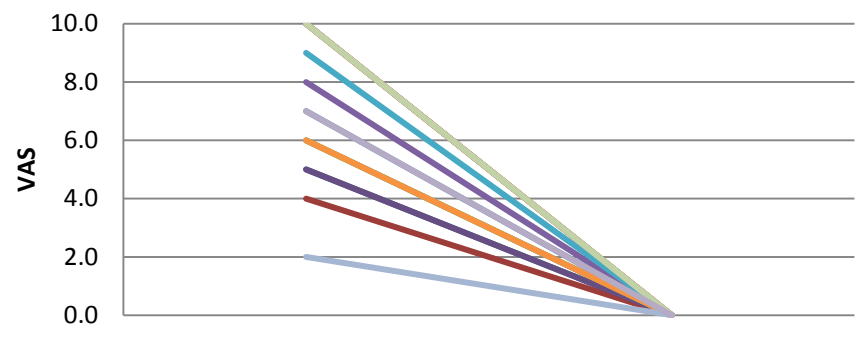

Figure 7: Pain perceived by each patient at baseline and at foot ulcer recovery measured with VAS score.

Because of these literature data showing results less satisfactory than the ones we observed while using Hyperoil", we're continuing to use Hyperoil" for the treatment of diabetic foot ulcers in WCU, to understand its possible use in earlier stages of the disease, too.

This case series suggest that using Hyperoil" for advanced diabetic foot ulcers might be a cheap and effective new option for the management of advanced diabetic foot ulcers.

These preliminary observations need to be scientifically evaluated in well-designed controlled studies where Hyperoil" has to be compared with available standard treatments.

\section{Acknowledgments}

The author thanks all patients and their relatives for having accepted to be included in this observation and for their consent to publish this case series, as all personnel in WCUs who have supported these patients. The author thanks Andrea Rossi for his friendly support in medical writing, Marzia Lugli and Oscar Maleti for their kind collaboration and ready effectiveness in their vascular surgery centre (Cardiovascular Department, Hesperia Hospital, Modena, Italy).

\section{References}

1. http://www.who.int/diabetes/facts/world_figures/en/http://www.who.int/ diabetes/facts/world figures/en/

2. Bos M, Agyemang C (2013) Prevalence and complications of diabetes mellitus in Northern Africa, a systematic review. BMC Public Health 25: 387.
3. Chan JC, Gagliardino JJ, Baik SH, Chantelot JM, Ferreira SR, et al. (2009) Multifaceted determinants for achieving glycemic control: the International Diabetes Management Practice Study (IDMPS). Diabetes Care 32: 227-233.

4. Seguel G (2013) An update on diabetic foot. Rev Med Chil 141: 1464-1469.

5. http://www.who.int/mediacentre/news/releases/2005/pr61/en/.\%20http:/www who.int/mediacentre/news/releases/2005/pr61/en/

6. American Diabetes Association (2008) Economic costs of diabetes in the U.S. in 2007. Diabetes Care 31: 596-615.

7. Driver VR, Fabbi M, Lavery LA, Gibbons G (2010) The costs of diabetic foot: the economic case for the limb salvage team. J Am Podiatr Med Assoc 100: 335-341.

8. Peleg AY, Weerarathna T, McCarthy JS, Davis TM (2006) Common infections in diabetes: pathogenesis, management and relationship to glycaemic control. Diabetes Metab Res Rev 23: 3-13.

9. Melmed S, Polonsky KS, Larsen PR, Kronenberg HM (2011) Williams Textbook of Endocrinology. (12thedn), Elsevier.

10. Dumville JC, Worthy G, Bland JM, Cullum N, Dowson C, et al. (2009) Larva therapy for leg ulcers (VenUS II): randomised controlled trial. BMJ 338: b773.

11. labichella ML (2013) The use of an extract of Hypericum perforatum and Azadirachta indica in advanced diabetic foot: an unexpected outcome. BM Case Rep pii: bcr2012007299.

12. Fernández-Montequín JI, Infante-Cristiá E, Valenzuela-Silva C, FrancoPérez N, Savigne-Gutierrez W (2007) Intralesional injections of Citoprot-P (recombinant human epidermal growth factor) in advanced diabetic foot ulcers with risk of amputation. International Wound Journal 4: 333-343.

13. Fagrell B, Lundberg G (1984) A simplified evaluation of vital capillary microscopy for predicting skin viability in patients with severe arterial insufficiency. Clin Physiol 4: 403-411.

14. Melillo E, Catapano G, Dell'Omo G, labichella L, Berchiolli R, et al. (1995) Transcutaneous oxygen and carbon dioxide measurement in peripheral vascular disease. Vasc Surg 29: 273-280.

15. Melillo E, Ferrari M, Balbarini A, Pedrinelli R (2005) Transcutaneous Gases Determination in Diabetic Critical Limb Ischemia. Diabetes Care 28: 2081-2082.

16. http://www.diabetes.org/living-with-diabetes/treatment-and-care/blood glucose-control/checking-your-blood-glucose.htmlhttp://www.diabetes.org/ living-with-diabetes/treatment-and-care/blood-glucose-control/checking-yourblood-glucose.htm

17. Furie KL, Kasner SE, Adams RJ, Albers GW, Bush RL, et al. (2011) Guidelines for the prevention of stroke in patients with stroke or transient ischemic attack: a guideline for healthcare professionals from the american heart association american stroke association. Stroke 42: 227-276.

18. SPS3 Study Group, Benavente OR, Coffey CS, Conwit R, Hart RG, et al (2013) Blood-pressure targets in patients with recent lacunar stroke: the SPS3 randomised trial. Lancet 382: 507-15.

19. Leriche R, Fontaine R (1927) Experimental Researches upon Vasomotricity. Ann Surg 85: 641-646.

20. Francisco J Serrano Hernandoa, Antonio Martín Conejeroa (2007) Periphera Artery Disease: Pathophysiology, Diagnosis and Treatment. Rev Esp Cardio 60: 969-982.

21. Mosti G, labichella ML, Partsch H (2012) Compression therapy in mixed ulcers increases venous output and arterial perfusion. Journal of Vascular Surgery 55: 122-128.

22. DeLoach LJ, Higgins MS, Caplan AB, Stiff JL (1998) The visual analog scale in the immediate postoperative period: intrasubject variability and correlation with a numeric scale. Anesth Analg 86: 102-106

23. Maier HM, Ilich JZ, Kim JS, Spicer MT (2013) Nutrition supplementation fo diabetic wound healing: a systematic review of current literature. Skinmed 11: 217-224.

24. Yera-Alos IB, Alonso-Carbonell L, Valenzuela-Silva CM, Tuero-Iglesias AD Moreira-Martínez M, et al. (2013) Active post-marketing surveillance of the intralesional administration of human recombinant epidermal growth factor in diabetic foot ulcers. BMC Pharmacol Toxicol 14: 44.

25. Sohn MW, Meadows JL, Oh EH, Budiman-Mak E, Lee TA, et al. (2013) Statin 
Citation: labichella ML (2015) The Use of a Mixture of Hypericum Perforatum and Azadirachta indica for the Management of Diabetic Foot Ulcers: A Case Series. J Diabetes Metab 6: 499. doi:10.4172/2155-6156.1000499

use and lower extremity amputation risk in nonelderly diabetic patients. Vasc Surg 58: 1578-1585.

26. Dumville JC, O'Meara S, Deshpande S, Speak K (2013) Hydrogel dressings for healing diabetic foot ulcers. Cochrane Database Syst Rev 7: CD009101.

27. Ambrosch A, Halevy D, Fwity B, Brin T, Lobmann R (2013) Effect of daptomycin on local interleukin-6, matrix metalloproteinase-9, and metallopeptidase inhibitor 1 in patients with MRSA-infected diabetic foot. Int J Low Extrem Wounds 12: 100-105.

28. Malik A, Mohammad Z, Ahmad J (2013) The diabetic foot infections: biofilms and antimicrobial resistance. Diabetes Metab Syndr 7: 101-107.

29. Yingsakmongkol N (2013) Clinical outcomes of WF10 adjunct to standard treatment of diabetic foot ulcers. J Wound Care 22: 130-136.

30. Alzahrani H, Bedir Y, Al-Hayani (2013) A Efficacy of shellac, a natural product, for the prevention of wet gangrene. J Int Med Res 41: 795-803.
31. Tzeng YS, Deng SC, Wang CH, Tsai JC (2013) Treatment of nonhealing diabetic lower extremity ulcers with skin graft and autologous platelet gel: a case series. Biomed Res Int 2013: 1-9.

32. Berlanga J, Fernández JI, López E, López PA, del Río A, et al. (2013) Heberprot-P: a novel product for treating advanced diabetic foot ulcer. MEDICC Rev 15: 11-15.

33. Sipahi S, Gungor O, Gunduz M, Cilci M, Demirci MC, et al. (2013) The effect of oral supplementation with a combination of beta-hydroxy-beta-methylbutyrate arginine and glutamine on wound healing: a retrospective analysis of diabetic haemodialysis patients. BMC Nephrol 14: 8 .

34. Ciammaichella G, Belcaro G, Dugall M, Hosoi M, Luzzi R, et al. (2012) Product evaluation of Ureadin Rx Db (ISDIN) for prevention and treatment of mild-tomoderate xerosis of the foot in diabetic patients. Prevention of skin lesions due to microangiopathy. Panminerva Med 54: 35-42. 